\title{
Enhanced therapeutic effects against murine colon carcinoma induced by a Colon 26/Ag85A-CD226 tumor cell vaccine
}

\author{
YAN LI ${ }^{1,2}$, FANGLI YANG $^{1}$, LIXUAN SANG ${ }^{1}$, JUNFENG ZHU ${ }^{1}$, XUE HAN $^{1}$, FENGPING SHAN ${ }^{1}$, \\ SHENGJUN LI ${ }^{1}$, JINGBO ZHAI ${ }^{1}$, DANAN WANG ${ }^{1}$, CHANGLONG LU $^{1}$ and XUN SUN ${ }^{1}$ \\ ${ }^{1}$ Department of Immunology, School of Basic Medical Science, China Medical University, Heping, Shenyang, \\ Liaoning 110001; ${ }^{2}$ Department of Immunology and Microbiology, Liaoning College of \\ Health Vocational Technology, Shenyang, Liaoning 110101, P.R. China
}

Received March 26, 2015; Accepted June 22, 2015

DOI: $10.3892 / o r .2015 .4137$

\begin{abstract}
Genetically modified tumor cells represent one of the most effective cancer vaccine strategies. In the present study, we describe our approach for inducing an immune response against a colon carcinoma in BALB/c mice, using a Colon 26 tumor cell line expressing Ag85A and CD226. We investigated whether $\mathrm{CD} 226$ plays a promotive role for Ag85A against Colon 26 colon carcinoma. The therapeutic efficacy was investigated. The cytotoxic T lymphocyte (CTL) and natural killer (NK) cell cytotoxicity were assessed. Dynamic changes in interferon (IFN)- $\gamma$ levels in the spleen and the number of IFN- $\gamma$-producing $\mathrm{CD}^{+}$or $\mathrm{CD} 8^{+} \mathrm{T}$ cells in the spleen or mesenteric lymph nodes were detected by enzyme-linked immunoabsorbent assay or flow cytometry. Extended survival times, delayed appearances of tumors, and reduced tumor volumes were achieved by preventive vaccination with the Colon 26/Ag85A-CD226 tumor cell vaccine. NK cell or CTL cytotoxicity in the spleens of mice immunized with the Colon 26/Ag85A-CD226 tumor cell vaccine was significantly higher than that in the other treatment groups. The numbers of $\mathrm{CD} 4^{+} \mathrm{IFN}-\gamma^{+}$and $\mathrm{CD} 8^{+} \mathrm{IFN}-\gamma^{+} \mathrm{T}$ cells were both significantly increased in mice immunized with the Colon 26/Ag85A-CD226 tumor cell vaccine in both the spleen and mesenteric lymph nodes. Our results indicated that the tumor vaccine expressing Ag85A and CD226 induced more intensive antitumor immunity than tumor vaccine expressing Ag85A or CD226 only. Moreover, the results suggest that $\mathrm{Ag} 85 \mathrm{~A}$ and CD226 play a synergistic antitumor effect and CD226 could be used as a genetic adjuvant to enhance the effects of Ag85A vaccine against murine colon carcinoma.
\end{abstract}

Correspondence to: Professor Changlong Lu, Department of Immunology, School of Basic Medical Science, China Medical University, 92 North Second Rood, Heping, Shenyang, Liaoning 110001, P.R. China

E-mail: changlonglyu@hotmail.com

Key words: colon carcinoma, Ag85A, CD226, tumor cell vaccine

\section{Introduction}

Colorectal cancer (CRC) is the third most common gastrointestinal malignancy worldwide, among which colon carcinoma is more frequent than rectal cancer (1). In developing countries, CRC is becoming increasingly prevalent, particularly in China (2). Currently, CRC is the fourth most lethal type of tumor in China (3), causing 715,000 new cases and 70,000 deaths annually (4). The prognosis of advanced CRC remains poor, and the estimated 5-year survival rate remains unsatisfactory due to metastasis, which leads to poor outcomes (5). Currently, conventional treatments, including radical surgery and adjuvant therapies, such as chemotherapy and radiation therapy, have been widely applied to the treatment of CRC; however, the 5-year survival rate remains low, and significant adverse events remain unresolved issues (6). Accordingly, there is an urgent need to develop novel strategies to manage CRC. Today, tumor immunotherapy for colon cancer is extremely appealing, and cancer vaccines have become an attractive therapeutic option that have the potential to control metastatic disease and prolong the time to recurrence without causing significant side-effects.

Antigen-85A (Ag85A) is a major protein secreted by Mycobacterium spp. that participates in the synthesis of mycolic acid in cell walls (7) and stimulates massive Th1 cell proliferation and cytokine production in humans or mice infected with mycobacteria (8). Mice vaccinated with Ag85A DNA exhibit elevated IL-2, interferon (IFN) $\gamma$ and IgG2a production, as well as increased cytotoxic $\mathrm{T}$ lymphocyte (CTL) activity in response to BCG proteins, of which Ag85A is a major component $(9,10)$. Numerous studies have shown that vaccination with recombinant $\mathrm{Ag} 85 \mathrm{~A}-\mathrm{DNA}$ induces a vigorous immune response that protects against tuberculosis in mice $(11,12)$. We have previously demonstrated that an orally administered Ag85A DNA vaccine induced systemic and mucosal immunity by inducing Th1 type immune responses to provide protection against Mycobacterium tuberculosis infection (13). In light of the role of Ag85A in inducing cellular immune responses, efforts are being made to apply single Ag85A or recombinant Ag85A DNA vaccines to the treatment of tumors. One study has shown that a recombinant Ag85A and GM-CSF DNA vaccine enhanced antitumor immunity 
against melanoma in mice (14). Our previous study indicated a robust therapeutic effect on bladder cancer through a dendritic cell vaccine designed to evoke immune responses against Ag85A (15).

CD226 is a transmembrane glycoprotein and member of the immunoglobulin superfamily that is constitutively expressed by the majority of T cells, natural killer (NK) cells, monocytes/macrophages, platelets and megakaryocytes, as well as by a subset of B cells (16). During T cell priming, CD226-mediated co-stimulatory signals can skew $\mathrm{CD}^{+} \mathrm{T}$ cell differentiation towards the Th1 cell pathway (17). Additionally, the CD226 molecule itself is an important activated receptor on the surface of NK cells, and is one of the main molecules involved in tumor recognition and NK cell-mediated cytotoxicity (18). Our recent study indicated that CD226 could be used as a genetic adjuvant to enhance both systemic and mucosal immune effects induced by an Ag85A DNA vaccine in normal mice (19). To optimize immunotherapy against colon carcinoma, we developed a tumor cell vaccine expressing Ag85A and CD226 and investigated its anti-colon carcinoma efficacy in $\mathrm{BALB} / \mathrm{c}$ mice.

\section{Materials and methods}

Mice and cell lines. Female BALB/c mice (6- to 8-weeks old) were purchased from Liao Ning Chang Sheng Biotechnology Co. (Benxi, China) and housed in pathogen-free conditions. The present study was carried out in strict accordance with the recommendations in the Guide for the Care and Use of Laboratory Animals of the National Institutes of Health. The protocol was approved by the Ethics Committee of the Animal Experiments of China Medical University. All surgery was performed under sodium pentobarbital anesthesia, and all efforts were made to minimize suffering. Yac-1 and Colon 26 cell lines were obtained from the Institute of Biochemistry and Cell Biology (Chinese Academy of Sciences, Shanghai, China), and cultured at $37^{\circ} \mathrm{C}$ in $5 \% \mathrm{CO}_{2}$ in a humidified atmosphere in complete RPMI-1640 medium (Thermo Scientific, Waltham, MA, USA), supplemented with $10 \%$ fetal bovine serum (FBS; Cell Culture Technologies, Tokyo, Japan), $100 \mathrm{U} / \mathrm{ml}$ penicillin $\mathrm{G}$ sodium and $100 \mu \mathrm{g} / \mathrm{ml}$ streptomycin sulfate (BI Biological Industries, Kibbutz Beit-Haemek, Israel).

Plasmids and primers. The pcDNA3.1-Ag85A and pcDNA3.1CD226 plasmids were constructed in our laboratory. The CD226-PCR2.1-ToPo plasmid was a gift from Professor Shibuya (University of Tsukuba, Tsukuba, Japan). Recombinant plasmid pcDNA3.1-Ag85A-CD226 was constructed as follows. The CD226 gene was first amplified from plasmid CD226-PCR2.1ToPo using a regular PCR routine. The amplicon was then inserted into pcDNA3.1-Ag85A to derive the recombinant plasmid pcDNA3.1-Ag85A-CD226. After transformation into E. coli DH5 $\alpha$, the recombinant plasmid DNA was prepared and characterized by digestion using restriction enzymes and sequence analysis. The polymerase chain reaction (PCR) primer sequences were as follows: $C D 226$ forward, 5'-ATAAG AATGCGGCCGCATGGCTTATGTTACTTGGCTTTT GG-3' and reverse, 5'-GCCTAGCGTCTAGATCGAGGTCTT GGTTTTGGTCTTC-3'; Ag85A forward, 5'-TTTCGCGGAT CCAGATGTTTTCCCGGCC-3' and reverse, 5'-CTGTTCGG
AATTCGGCGCCCTGGG-3'; $\beta$-actin forward, 5'-TTCTTGG GTATGGAATCCTGTG-3' and reverse, 5'-GAGGAGCAATG ATCTTGATCTT-3'.

Stable transfection and construction of tumor cell vaccines. Colon 26 cells were cultured in complete media in 6-well plates. The recombinant plasmids pcDNA3.1-Ag85A-CD226, pcDNA3.1-Ag85A or pcDNA3.1-CD226, or a mock plasmid, pcDNA3.1 were transfected into Colon 26 cells at $\sim 80 \%$ confluency with Lipofectamine ${ }^{\mathrm{TM}} 2000$ reagent (Invitrogen, Carlsbad, CA, USA) according to the manufacturer's protocol. The stably expressing Ag85A or CD226 cell lines were selected in RPMI-1640 media containing $800 \mu \mathrm{g} / \mathrm{ml} \mathrm{G} 418$ (Invitrogen). After 21 days, G418-resistant clones were selected, and cells expressing Ag85A were termed 'Colon 26/Ag85A cells', cells expressing CD226 were termed 'Colon 26/CD226 cells', cells expressing Ag85A and CD226 were termed 'Colon 26/Ag85A-CD226 cells', cells transfected with mock plasmid pcDNA3.1 were termed 'Colon 26/pcDNA3.1 cells' and untransfected Colon 26 cells were used as an additional control. Total RNA and total cell proteins from each transfected cell were collected and extracted. The expression levels of $C D 226$ and $A g 85 A \mathrm{mRNA}$ were characterized by reverse transcriptase (RT)-PCR, and the protein expression levels of CD226 and Ag85A were characterized by western blotting using goat anti-mouse DNAM-1 and mouse anti-Ag85 (both from Santa Cruz Biotechnology, Santa Cruz, CA, USA), respectively.

Tumor vaccine-based immunotherapy in a murine model. $\mathrm{BALB} / \mathrm{c}$ mice were randomly divided into five groups, with nine mice per group. Each mouse was subcutaneously (s.c.) inoculated with $1 \times 10^{6}$ Colon 26 cells in the flank and 3 days later mice in each group were immunized with $1 \times 10^{7}$ Colon 26, Colon 26/pcDNA3.1, Colon 26/CD226, Colon 26/Ag85A or Colon 26/Ag85A-CD226 cells, previously inactivated by treatment with $100 \mu \mathrm{g} / \mathrm{ml}$ mitomycin C (Inalco SPA, Milan, Italy) three times at weekly intervals in the same flank that was initially challenged with Colon 26 cells. The five groups of mice included a normal control, pcDNA3.1, Ag85A, CD226 and Ag85A-CD226 group. Tumor growth was monitored by observing the onset of subcutaneous tumors and measuring two perpendicular tumor diameters using Vernier calipers. After onset, the tumor volume, tumor weight and percent survival (over a 70 day period) were evaluated. Tumor volume (V) was calculated using the formula: $\mathrm{V}\left(\mathrm{mm}^{3}\right)=0.523 \times \mathrm{L} \times \mathrm{W}^{2}$, in which $\mathrm{L}(\mathrm{mm})$ and $\mathrm{W}(\mathrm{mm})$ indicated the length and width of the tumor, respectively. One week after the final immunization, the mice were euthanized and sera, splenocytes and peripheral lymph node cells were isolated. Tumors were removed by dissection and fixed in $10 \%$ formalin.

Histopathological analysis. The formalin-fixed tissues were embedded in paraffin and then sectioned for hematoxylin and eosin (H\&E) staining and immunohistochemical analysis of tumors using a SABC-AP (rat IgG) immunohistochemical staining kit (Boster, Wuhan, China) according to the manufacturer's protocol. Sections were washed with phosphate-buffered saline (PBS) twice for $5 \mathrm{~min} /$ wash. After blocking with $0.1 \mathrm{mg} /$ 
ml BSA for $20 \mathrm{~min}$ at room temperature, the sections were incubated with monoclonal rat anti-mouse CD8 (LifeSpan BioSciences, Seattle, WA, USA) or monoclonal rat anti-mouse CD4 (Santa Cruz Biotechnology) at $4^{\circ} \mathrm{C}$ overnight. Sections were washed three times with PBS and then incubated with biotin-rabbit anti-rat $\mathrm{IgG}$ for $20 \mathrm{~min}$ at $37^{\circ} \mathrm{C}$. Subsequently, the sections were incubated with SABC-AP secondary antibody for $20 \mathrm{~min}$ at $37^{\circ} \mathrm{C}$. Slides were viewed using a microscope at a magnification of $\mathrm{x} 400 ; 10$ high-power fields containing the positive cells were randomly selected, and the average number of positive cells was determined by counting. Tumor samples were analyzed to detect the ratio of apoptotic cells by the terminal deoxynucleotidyl transferase-mediated dUTP-biotin nick end-labeling (TUNEL) method, using an apoptosis In Situ Detection kit (Wako Pure Chemical, Osaka, Japan), according to the manufacturer's instructions. TUNEL-positive cells were stained by DAB. The frequency of DAB-positive cells is shown, and the average percentage of DAB-positive staining was quantified from 10 randomly selected high-power fields (magnification, $\mathrm{x} 400$ ) of each section using ImmunoRatio or blinded manual cell counting (20).

CTL and NK cell CFSE/PI cytotoxicity assays using flow cytometry. The NK cell cytotoxicity assay was preformed as follows, and was based on protocols described elsewhere $(21,22)$. Briefly, Yac-1 cells (used as target cells) in the logarithmic growth phase $\left(2 \times 10^{7}\right.$ cells $\left./ \mathrm{ml}\right)$ were resuspended and labeled with $2.5 \mu \mathrm{M}$ fluorescein-based dye 5-(and -6)-carboxyfluorescein diacetate succinimidyl ester (CFSE; eBioscience, San Diego, CA, USA), and then incubated in RPMI-1640 medium (Thermo Scientific) containing 10\% FBS at $37^{\circ} \mathrm{C}$ under $5 \% \mathrm{CO}_{2}$ for $15 \mathrm{~min}$ in a $1 \mathrm{ml}$ volume. After the incubation, $1 \mathrm{ml} \mathrm{FCS}$ was added to stop the reaction. The cell suspensions were centrifuged for $5 \mathrm{~min}$ at $400 \mathrm{x} \mathrm{g}$, washed twice with PBS and resuspended in RPMI-1640 at a final concentration of $2 \times 10^{5}$ cells $/ \mathrm{ml}$. Splenocytes (used as effector cells) were purified from the immunized mice 1 week after the third immunization, enriched from the splenic homogenate using a Ficoll gradient (Sigma) and resuspended at a final concentration of $1 \times 10^{6}$ cells $/ \mathrm{ml}$.

The effector $(\mathrm{E})$ and target $(\mathrm{T})$ cells were added together to yield an E:T ratio of 5:1, and were incubated at $37^{\circ} \mathrm{C}$ under $5 \% \mathrm{CO}_{2}$ for $4 \mathrm{~h}$. After incubation, the tubes were mixed gently, placed on ice and $4 \mu \mathrm{l}$ propidium iodide (PI; $1 \mu \mathrm{g} / 1$, final concentration; Sigma-Aldrich, St. Louis, MO, USA) was added to each tube for 10-15 min. Finally, the samples were analyzed by flow-cytometry within $60 \mathrm{~min}$. All samples were analyzed on a FACSCalibur (Becton-Dickinson, San Diego, CA, USA), and flow cytometry data were analyzed using WINMDI 2.9 software. During data acquisition, a 'live gate' was set on the CFSE-stained target cell population using an FL1-histogram, and the CFSE-stained target cells were further gated on the PI-stained target cell population using an FL3-histogram.

The percentage of specific target cell death (cytotoxicity) was expressed as: \{[dead target cells in the sample (\%) - spontaneously dead target cells (\%)]/100\% - spontaneously dead target cells $(\%)\}$ x 100 . Control tubes containing target or effector cells alone were also assayed to facilitate the gating and marker settings. The fraction of target cells that spontaneously died was determined based on the number of target cells labeled with CFSE and incubated without effector cells for $4 \mathrm{~h}$.

The CTL cytotoxicity assay was preformed as follows. Briefly, $5 \times 10^{6}$ murine splenocytes (used as effector cells) were resuspended in 10\% RPMI-1640 medium in 24-well plates, and then were incubated for $72 \mathrm{~h}$ with $5 \times 10^{4}$ Colon 26 cells inactivated with mitomycin C (100 $\mu \mathrm{g} / \mathrm{ml})$. Additionally, $10 \mathrm{ng}$ rIL-2 (R\&D Systems, Minneapolis, MN, USA) was added to all wells except for the control samples with target cells alone. Cells were isolated from the splenic homogenate using a Ficoll gradient, and then were rinsed extensively with complete RPMI-1640 (1×10 6 cells $/ \mathrm{ml}$, final concentration) and used in the CTL cytotoxicity assay. Colon 26 cells $\left(2 \times 10^{5}\right.$ cells $/ \mathrm{ml}$, final concentration) were used as target cells. The operation process and analysis methods were the same as for the NK cytotoxicity assay.

ELISA assay analysis. At 0, 1, 2, 3 and 4 weeks after immunization, some mice were euthanized and splenocytes were isolated. Splenocytes $\left(2 \times 10^{7}\right.$ cells $\left./ \mathrm{ml}\right)$ purified from the immunized mice were stimulated with $5 \mu \mathrm{g} / \mathrm{ml}$ ConA in 24-well plates and were incubated for $72 \mathrm{~h}$ with $2 \times 10^{4}$ Colon 26 cells inactivated with mitomycin $\mathrm{C}(100 \mu \mathrm{g} / \mathrm{ml})$. The levels of IFN- $\gamma$ in the culture supernatants were determined using enzyme-linked immunoabsorbent assay (R\&D Systems) according to the manufacturer's instructions. Absorbance was measured at $450 \mathrm{~nm}$ using a microplate reader (Thermo), and the concentration of IFN- $\gamma$ was calculated using the software SoftMax Pro 4.3.1 LS.

Intracellular cytokine staining. Splenocytes and peripheral lymph node cells $\left(2 \times 10^{6}\right.$ cells $\left./ \mathrm{ml}\right)$ were isolated from the immunized mice. Cells were incubated for $72 \mathrm{~h}$ with $5 \times 10^{4}$ Colon 26 cells inactivated with mitomycin C $(100 \mu \mathrm{g} / \mathrm{ml})$ and then stimulated with $50 \mathrm{ng} / \mathrm{ml}$ PMA and $1 \mu \mathrm{g} / \mathrm{ml}$ ionomycin (Sigma) in the presence of $2 \mu \mathrm{M}$ monensin (BD Biosciences, San Jose, CA, USA) for 5 h. Cells were harvested and stained with Fc $\gamma$ receptor-blocking $\mathrm{mAb}$ (CD16/32; BD Biosciences), and then stained with fluorescein isothiocyanate (FITC)-conjugated rat anti-mouse CD4, PE-conjugated rat anti-mouse CD8 and $\mathrm{PE} / \mathrm{Cy} 7$-conjugated rat anti-mouse CD3 (all from Biolegend, San Diego, CA, USA) at $4^{\circ} \mathrm{C}$ for $30 \mathrm{~min}$. FITC mouse IgG2a, $\kappa$; $\mathrm{PE}$ rat $\mathrm{IgG} 2 \mathrm{a}, \kappa$; and $\mathrm{PE} / \mathrm{Cy} 7$ rat $\mathrm{IgG} 2 \mathrm{~b}, \kappa$ (Biolegend) were used as isotype controls. Cells were washed with PBS three times, fixed with fixation buffer at $4^{\circ} \mathrm{C}$ for $20 \mathrm{~min}$, permeabilized with the appropriate solution at room temperature for $20 \mathrm{~min}$, and then stained with APC-conjugated rat anti-mouse IFN- $\gamma$; APC-rat IgG1, $\kappa$ (both from Biolegend) was used as an isotype control. The percentage of IFN- $\gamma$-secreting CD4 $4^{+}$ and $\mathrm{CD}^{+} \mathrm{T}$ cells was determined using a FACSCalibur flow cytometer (Becton-Dickinson) and WINMDI 2.9 software.

Statistical analysis. Results are expressed as means \pm SD. The statistical significance of differences between groups was analyzed by two-tailed independent Student's t-tests. The one-way ANOVA analysis was performed when more than two groups was compared. Analyses were performed using GraphPad Prism 5.0 statistical software package (Graph Pad Inc., USA). In all instances, $\mathrm{p}<0.05$ was considered to indicate a statistically significant result. 


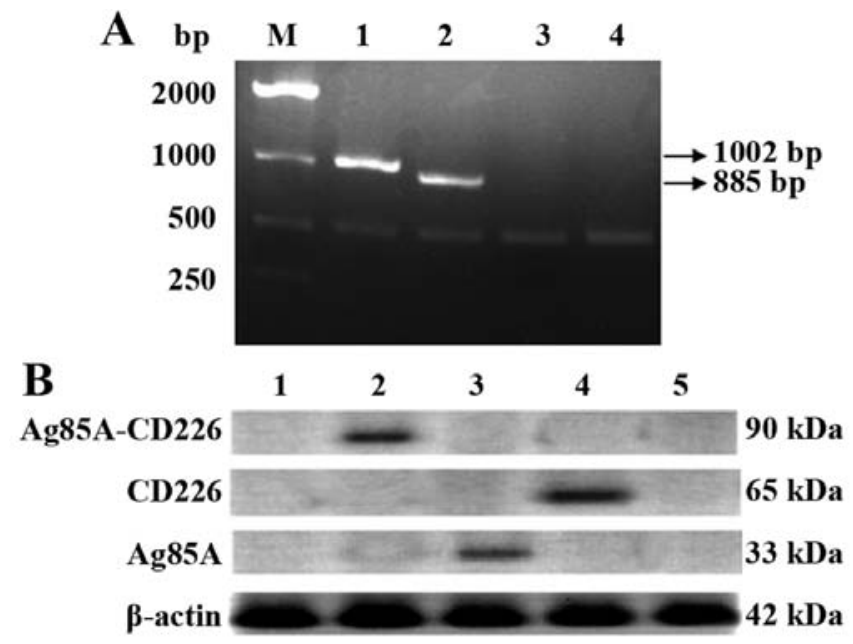

Figure 1. Characterization of the mRNA and protein levels of CD226 and Ag85A in Colon 26 cells. (A) Characterization of the expression of CD226 and Ag85A mRNA. M, DNA molecular ladder; lane 1,CD226 or $\beta$-actin mRNA expression in Colon 26 cells transfected with pcDNA3.1-Ag85A-CD226; lane 2, Ag85A or $\beta$-actin mRNA expression in Colon 26 cells transfected with pcDNA3.1-Ag85A-CD226; lane 3, mRNA in Colon 26 cells transfected with pcDNA3.1; lane 4, mRNA in untransfected Colon 26 cells. (B) Characterization of protein expression levels in Colon 26 cells transfected with different recombinant plasmids among total cellular protein lysates. Lane 1, proteins in untransfected Colon 26 cells; lane 2, fusion protein Ag85A-CD226 or $\beta$-actin protein expression in Colon 26 cells transfected with pcDNA3.1-Ag85A-CD226; lane 3, Ag85A or $\beta$-actin protein expression in Colon 26 cells transfected with pcDNA3.1-Ag85A; lane 4,CD226 or $\beta$-actin protein expression in Colon 26 cells transfected with pcDNA3.1-CD226; lane 5, proteins in Colon 26 cells transfected with pcDNA3.1.

\section{Results}

Expression of CD226 and Ag85A in Colon 26 cells. The recombinant pcDNA3.1-Ag85A-CD226 plasmid was constructed and characterized by endonuclease digestion and DNA sequencing (data not shown). The expression of Ag85A and CD226 in the pcDNA3.1-Ag85A-CD226 plasmid was confirmed by RT-PCR and western blotting after stable transfection of the recombinant plasmid into Colon 26 cells. Both CD226 and Ag85A were successfully expressed at both the mRNA and protein levels in the Colon 26 cells (Fig. 1A and B).

Therapeutic efficacy against Colon 26 tumors using a Colon 26/Ag85A-CD226-pcDNA3.1 tumor cell vaccine. We investigated the therapeutic tumor efficacy of a tumor vaccine expressing Ag85A and CD226. We detected a noticeable effect of the antitumor immune therapy in mice immunized with the Colon 26/Ag85A-CD226 tumor cell vaccine. Under the same experimental conditions, measurable tumors were detected in all mice injected with $5 \times 10^{6}$ inactivated Colon 26 cells on day 28. We found that the volume and weight of tumors were the smallest in the Colon 26/Ag85A-CD226 cell vaccine group when compared with the Colon 26 cell vaccine group, Colon 26/pcDNA3.1 cell vaccine group, Colon 26/Ag85A cell vaccine group or Colon $26 / \mathrm{CD} 226$ cell vaccine group on day 28 (Fig. 2A-C). Based on our previous study, $2 \times 10^{6}$ Colon 26 cells in logarithmic grown phase were inoculated into BALB/c mice, which usually generated a palpable tumor in $\sim 7$ days. However, the tumor growth was not palpable in all mice treated with the different tumor cell vaccines until 11 days into the observation, except for the Colon 26 and Colon 26/pcDNA3.1 cell vaccine groups. Furthermore, the survival time of mice vaccinated with the Colon 26/ Ag85A-CD226 vaccine was the longest, and the survival time of mice vaccinated with the Colon $26 / \mathrm{Ag} 85 \mathrm{~A}$ or Colon 26/ CD226 vaccine was significantly longer than that of the mice vaccinated with the Colon 26/pcDNA3.1 or Colon 26 vaccine ( $<<0.01 ;$ Fig. 2D). It appeared that the therapeutic effect of the Colon 26/Ag85A-CD226 tumor cell vaccine was the strongest in all of the five vaccine groups.

Tumor histopathology analysis. Tumor tissues were fixed and stained. H\&E staining of the tumor sections showed the active growth of tumor cells, with obvious nuclear division and rich vessels in both the Colon 26/pcDNA3.1 and Colon 26 tumor cell vaccine groups (Fig. 3A-a and -b). In the Colon 26/CD226 tumor cell vaccine group, tumor cells grew slowly and few inflammatory cells infiltrated the tumor tissues (Fig. 3A-c). In the Colon 26/Ag85A tumor cell vaccine group, the infiltration of inflammatory cells was increased appreciably and central necrosis was noticeable in the tumor tissues (Fig. 3A-d). In the Colon 26/Ag85A-CD226 tumor cell vaccine group, massive numbers of inflammatory cells infiltrating the tumor tissues could be observed, massive necrosis in tumor tissues was visible and the tumors had obviously shrunk, experienced ordered rarefaction and had degenerated (Fig. 3A-e). The TUNEL staining results indicated that the maximum percentage of apoptosis could be detected in the samples from the Colon 26/Ag85A-CD226 tumor cell vaccinetreated mice (Fig. 3B and C). The immunohistochemical staining results indicated that the infiltration of $\mathrm{CD} 4^{+}$or $\mathrm{CD}^{+} \mathrm{T}$ cells increased significantly in the tumor tissues of the Colon 26/Ag85A-CD226 tumor cell vaccine group compared with that in other tumor cell vaccine groups (Fig. 3D and E). Histopathology analyses suggested that the Ag85A and CD226 genes alone or in combination induced a cellular immune response against colon carcinoma cells, and that the antitumor effect induced by the Colon 26/Ag85A-CD226 tumor cell vaccine was the strongest.

Detection of NK cell and CTL cytotoxicity in splenocytes. To examine whether the CTL and NK cell cytotoxicity was 
$\mathbf{A}$

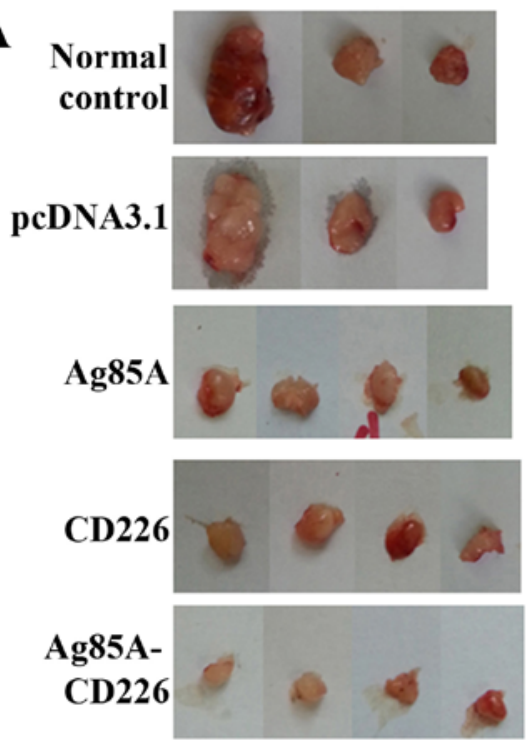

B

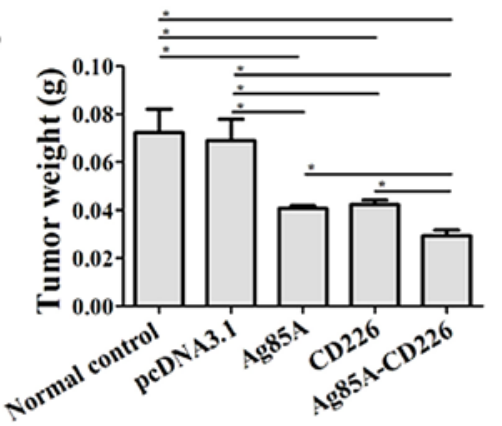

C

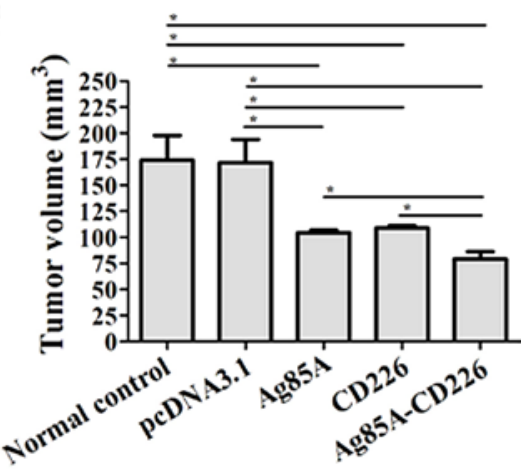

D

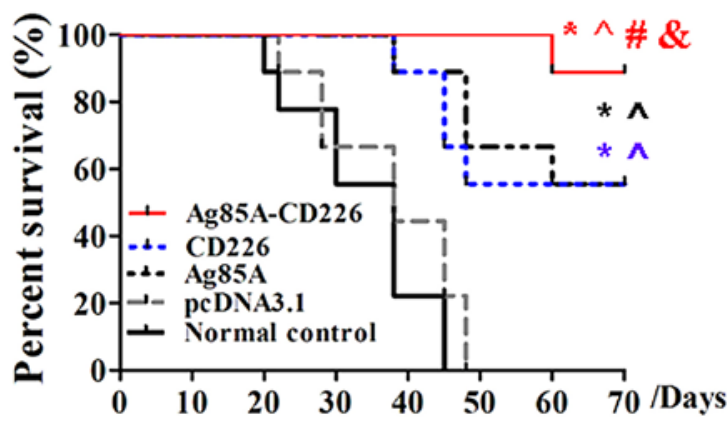

Figure 2. Therapeutic effects of the tumor cell vaccines. (A) Representative images of tumor tissues 28 days after treatment. (B) Statistical analyses of the tumor weights in mice from each group 28 days after treatment. (C) Statistical analyses of tumor volumes in mice from each group 28 days after treatment. Data are expressed as means \pm SD $(n=5)$, and one representative of three experiments is shown; ${ }^{*} \mathrm{p}<0.05,{ }^{* *} \mathrm{p}<0.01$. (D) The survival time of mice in each group 70 days after treatment was analyzed by the Kaplan-Meier method. Kaplan-Meier survival curves are shown; ${ }^{*}$ p $<0.01$ vs. the control group, ${ }^{\wedge}$ p $<0.01$ vs. the pcDNA3.1 group, ${ }^{\#} \mathrm{p}<0.01$ vs.the CD226 group, ${ }^{\&} \mathrm{p}<0.01$ vs. the Ag85A group.

enhanced in mice vaccinated with the Colon 26/Ag85A-CD226 tumor cell vaccine, splenocytes from each group were purified at day 7 after the third immunization. We found that the NK cell cytotoxicity of splenocytes from the mice immunized with the Colon 26/Ag85A-CD226 tumor cell vaccine was significantly greater than that of the Colon 26/Ag85A, Colon 26/CD226, Colon 26/pcDNA3.1 or Colon 26 tumor cell vaccine treated mice ( $<<0.01$; Fig. 4A and C). The experimental results of CTL cytotoxicity were consistent with that of NK cell cytotoxicity ( $<<0.01$; Fig. 4B and D). The findings suggested that the Colon 26/Ag85A-CD226 tumor cell vaccine induced the generation of the strongest $\mathrm{NK}$ cell and CTL cytotoxicity in mice.

IFN- $\gamma$ levels in splenocytes immunized with the Colon 26/ Ag85A-CD226 tumor cell vaccine. We found that IFN- $\gamma$ levels in splenocytes gradually increased from 1 to 4 weeks of immunization in the mice treated with the various tumor cell vaccines (Fig. 5). The IFN- $\gamma$ levels in splenocytes from mice immunized with the Colon 26/Ag85A-CD226 or
Colon 26/Ag85A tumor cell vaccines increased slowly in the first 2 or 3 weeks, respectively, of immunization and then increased rapidly thereafter. IFN- $\gamma$ levels in splenocytes from mice immunized with the Colon 26/CD226 tumor cell vaccine increased slowly throughout the entire 4 weeks of immunization. In the mice immunized with the Colon 26/pcDNA3.1 or Colon 26 tumor cell vaccines, IFN- $\gamma$ levels increased slowly in the first 3 weeks of immunization, and then showed a trend to decline. Finally, the IFN- $\gamma$ levels in splenocytes from mice immunized with the Colon 26/Ag85A-CD226 tumor cell vaccine were significantly higher than those in mice treated with the Colon 26/Ag85A, Colon 26/CD226, Colon 26/pcDNA3.1 or Colon 26 tumor cell vaccines $(\mathrm{p}<0.01)$ at the 4 th week. The findings suggest that the Colon 26/Ag85A-CD226 tumor vaccine stimulates the IFN- $\gamma$ production at higher levels compared with the Colon 26/Ag85A or Colon 26/CD226 tumor cell vaccines.

Enhanced Th1 cell-dominated cellular immunity antitumor responses induced by the tumor cell vaccine. 


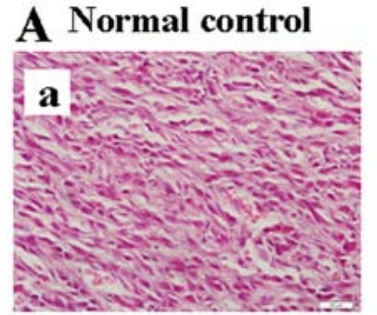

CD226

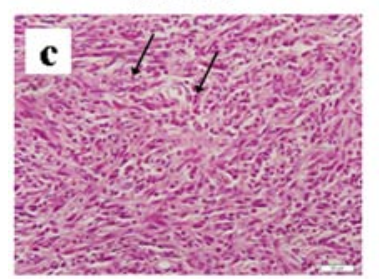

pcDNA3.1

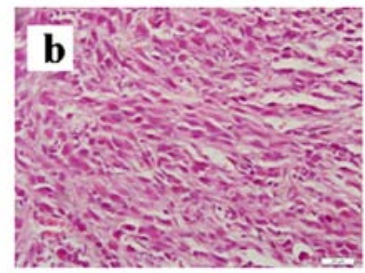

Ag85A

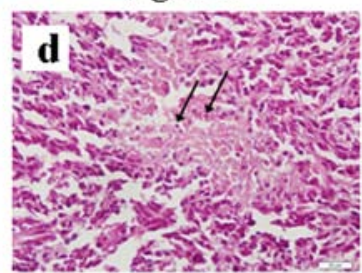

Ag85A-CD226

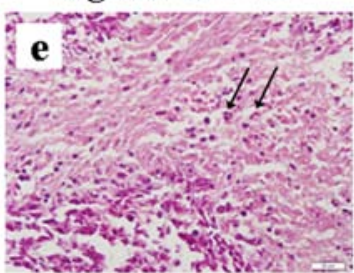

\section{B Normal control}

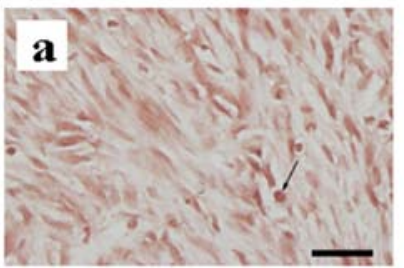

CD226

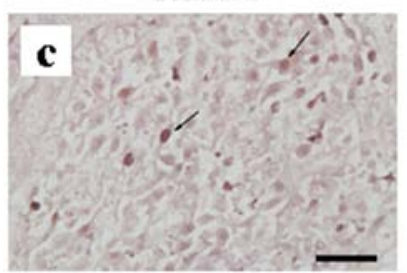

pcDNA3.1

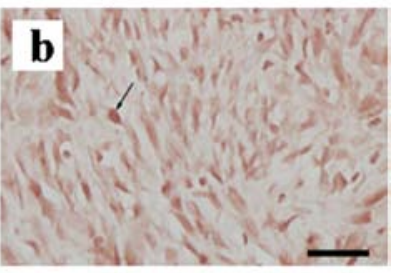

$\operatorname{Ag85A}$

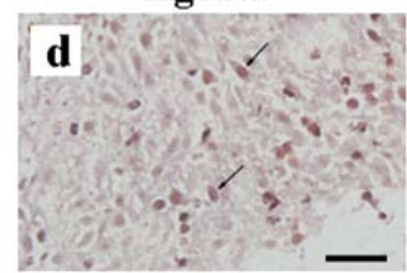

Ag85A-CD226

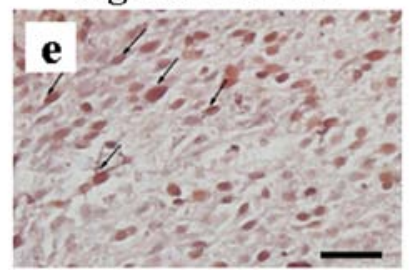

C

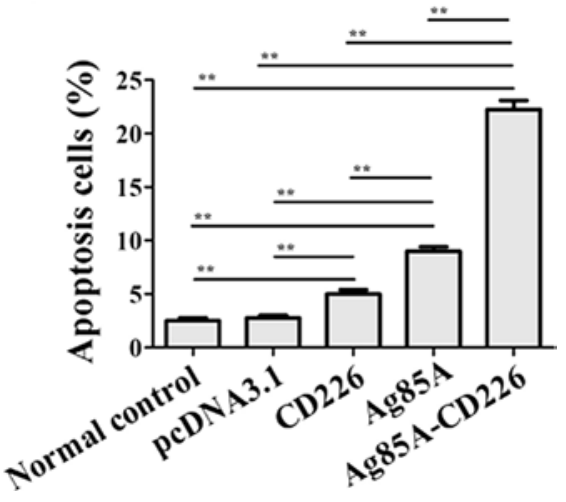

\section{D1}

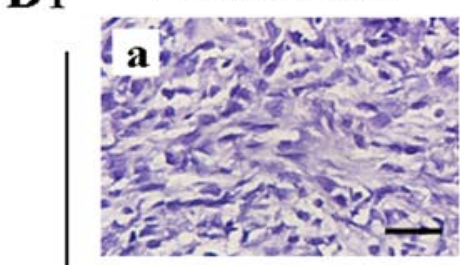

CD226

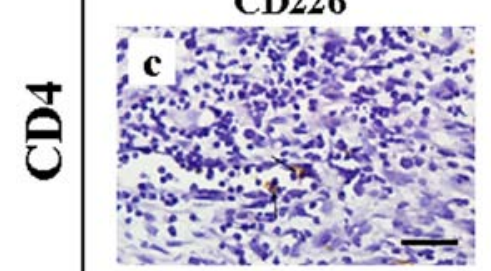

Ag85A-CD226

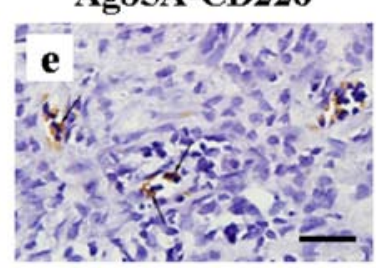

pcDNA3.1

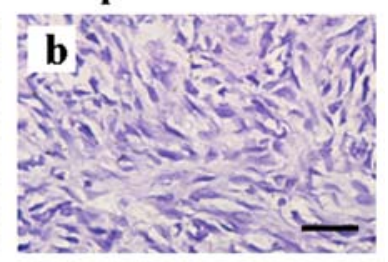

Ag85A

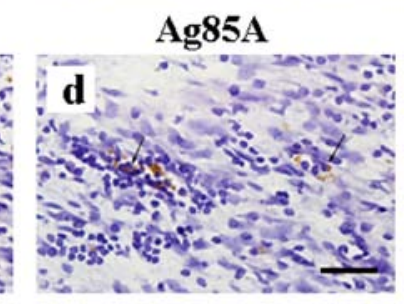

.

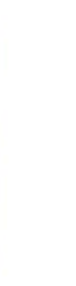

Figure 3. Histopathological analysis of tumor tissues. (A) Histopathology of the tumor tissues from the BALB/c mice (H\&E, magnification, $\mathrm{x} 400$ ). (a and b) Histopathological tumor tissue sections in mice treated with Colon 26 tumor cells or Colon 26/pcDNA3.1 tumor cells, respectively, wherein the tumor cells grew actively and rich vessels were observed along with obvious nuclear division. (c) Histopathological tumor tissue sections in mice treated with the Colon 26/CD226 tumor cell vaccine, wherein the tumor cells grew slowly, a small amount of inflammatory infiltrates could be observed, and vessels in the tumor tissue were significantly reduced. (d) Histopathological tumor tissue sections in mice treated with the Colon 26/Ag85A tumor cell vaccine, wherein the tumor cells grew slowly, few inflammatory cells could be observed infiltrating the tumor tissue, and there was evidence of central necrosis in the tumor tissue. (e) Histopathological tumor tissue sections in mice treated with the Colon 26/Ag85A-CD226 tumor cell vaccine, wherein the infiltration of lymphocytes, monocytes and neutrophils increased appreciably and massive necrosis in tumor tissues was visible, vessels were not visible and visible connective tissue around tumors and surrounding tissues appeared. Black arrows indicate inflammatory cells. (B) A representative DAB immunohistochemistry micrograph for apoptotic cells in tumor tissues by TUNEL staining (magnification, $\mathrm{x} 400$ ). Black arrows indicate examples of DAB-positive nuclei. Scale bar, $20 \mu \mathrm{m}$. (C) Percentage of TUNEL-positive tumor cells. $\left(D_{1}\right)$ Immunohistochemical staining for CD4 ${ }^{+} \mathrm{T}$ cells in tumor tissues (magnification, $\mathrm{x} 400$ ). Black arrows indicate $\mathrm{CD}^{+} \mathrm{T}$ cells. (E) The absolute number of infiltrating CD4 ${ }^{+} \mathrm{T}$ cells in the tumor was counted under a light microscope. Scale bar, $20 \mu \mathrm{m}$. Data are expressed as means $\pm \mathrm{SD}(\mathrm{n}=5)$, and one representative of three individual experiments is shown; ${ }^{*} \mathrm{p}<0.05,{ }^{* *} \mathrm{p}<0.01$. 

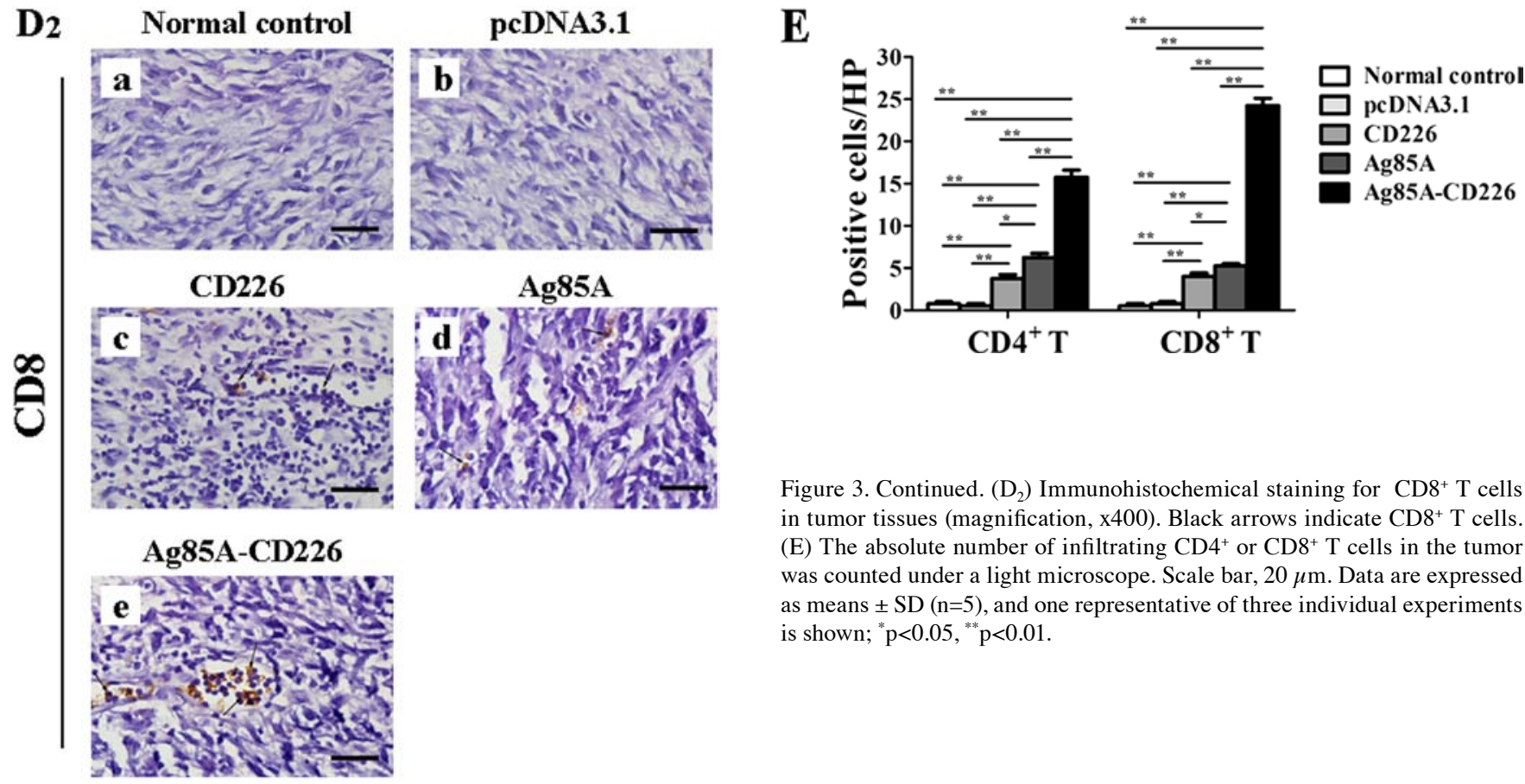

Figure 3. Continued. $\left(\mathrm{D}_{2}\right)$ Immunohistochemical staining for $C D 8^{+} \mathrm{T}$ cells in tumor tissues (magnification, $\mathrm{x} 400$ ). Black arrows indicate $\mathrm{CD} 8^{+} \mathrm{T}$ cells. (E) The absolute number of infiltrating $\mathrm{CD} 4^{+}$or $\mathrm{CD} 8^{+} \mathrm{T}$ cells in the tumor was counted under a light microscope. Scale bar, $20 \mu \mathrm{m}$. Data are expressed as means $\pm \operatorname{SD}(n=5)$, and one representative of three individual experiments is shown; ${ }^{*} \mathrm{p}<0.05,{ }^{* *} \mathrm{p}<0.01$.

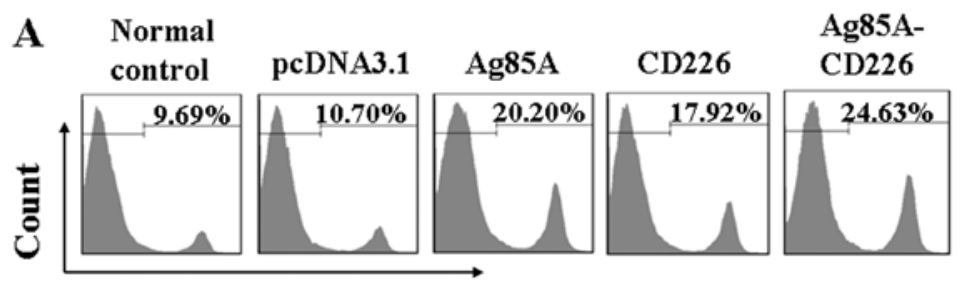

PerCP-PI

Gated on Yac-1 cells

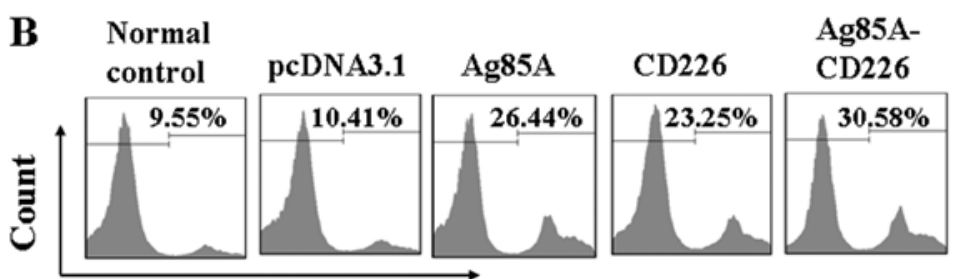

PerCP-PI

\section{Gated on Colon 26 cells}

C

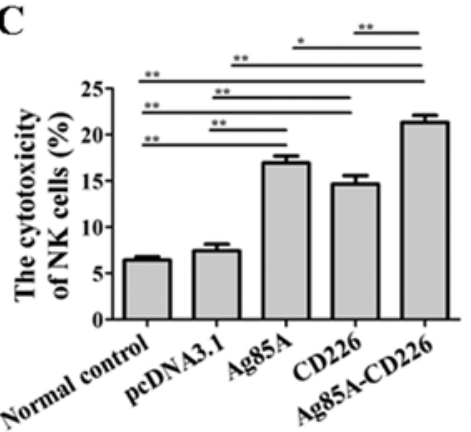

D

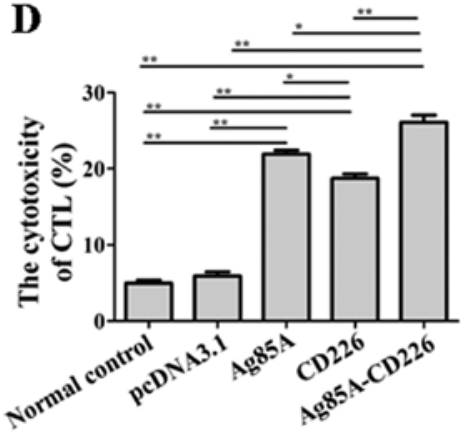

Figure 4. Flow cytometry-based detection of NK cell and CTL cytotoxic activity in splenocytes. (A) Representative flow cytometric profiles of NK cell cytotoxicity. After CFSE (FITC)-positive target cells (Yac-1 cells) were gated, the PI (PerCP) histogram was then used to determine the proportion of dead target cells. The proportion of spontaneously dead target cells was 3.27\% (data not shown). (B) Representative flow cytometry profiles of CTL cytotoxicity. After CFSE (FITC)-positive target cells (Colon 26 cells) were gated, the PI (PerCP) histogram was used to determine the proportion of dead target cells. The proportion of spontaneously dead target cells was $4.57 \%$ (data not shown). (C) NK cell cytotoxicity statistics. (D) CTL cytotoxicity statistics. Data are expressed as means $\pm \mathrm{SD}(\mathrm{n}=5)$, and one representative of three experiments is shown; ${ }^{\mathrm{p}}<0.05,{ }^{* *} \mathrm{p}<0.01$. NK, natural killer; CTL, cytotoxic T lymphocyte; PI, propidium iodide. 


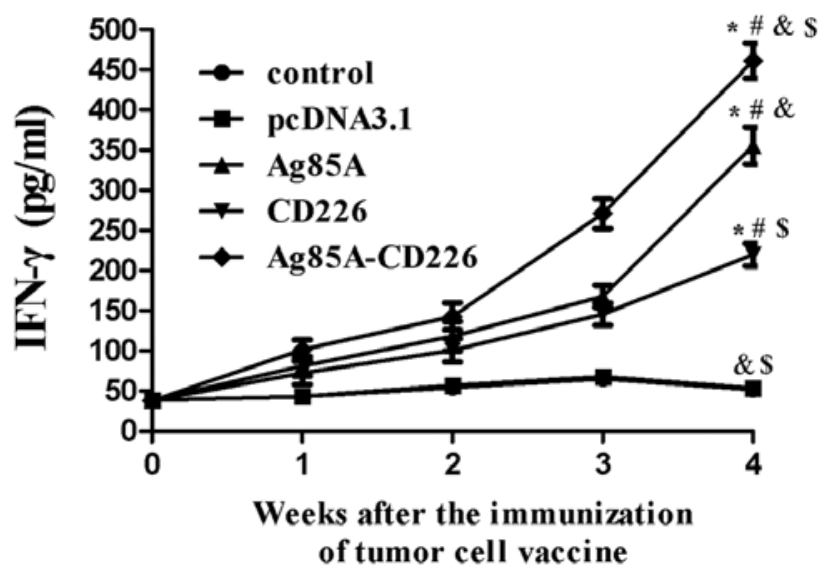

Figure 5. IFN- $\gamma$ expression induced by the Colon 26/Ag85A-CD226 tumor cell vaccine in splenocytes. IFN- $\gamma$ production by splenocytes was analyzed by enzyme-linked immunoabsorbent assay. Data are representative of three independent experiments and are shown as means $\pm \mathrm{SD}(\mathrm{n}=5)$; ${ }^{*} \mathrm{p}<0.01 \mathrm{vs}$. control group, ${ }^{\sharp} \mathrm{p}<0.01$ vs. the pcDNA3.1 group, ${ }^{\circledR} \mathrm{p}<0.01$ vs. the CD226 group, ${ }^{\$} \mathrm{p}<0.01$ vs. the $\mathrm{Ag} 85 \mathrm{~A}$ group.

A

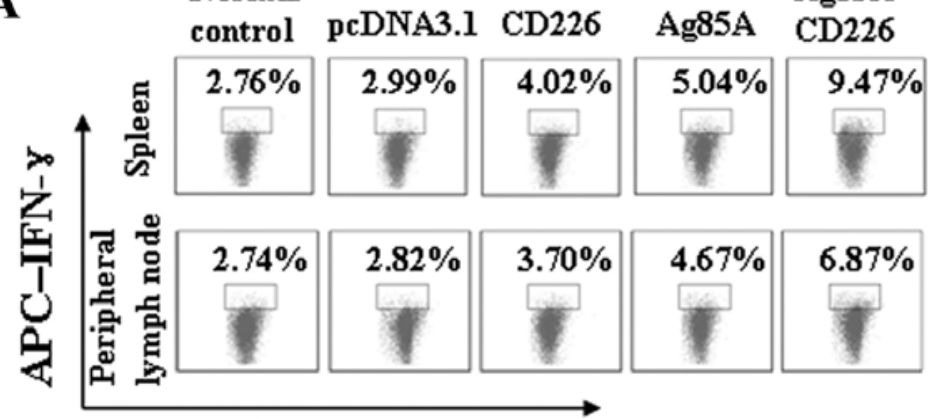

FITC-CD4

Gated on $\mathrm{CD}^{+} \mathrm{T}$ cells

C

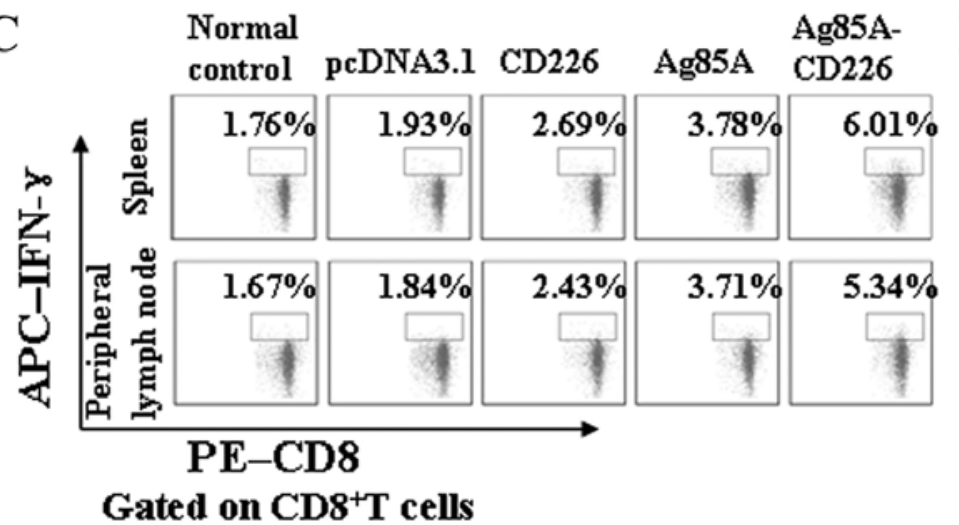

B

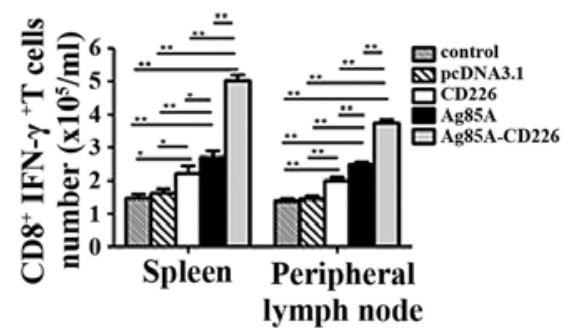

D

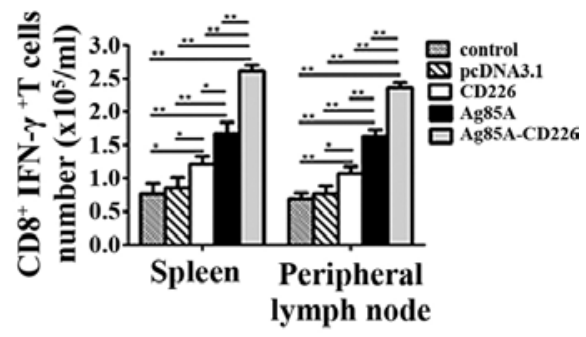

Figure 6. Percentage of IFN- $\gamma$-secreting $\mathrm{CD}^{+}$and $\mathrm{CD}^{+} \mathrm{T}$ cells in splenocytes and peripheral lymph node cells. (A) Representative flow cytometric profiles and (B) the percentage of $\mathrm{CD} 4^{+} \mathrm{IFN}-\gamma^{+} \mathrm{T}$ cells in splenocytes and peripheral lymph node cells gated on $\mathrm{CD} 3^{+} \mathrm{CD} 4^{+} \mathrm{T}$ cells are shown. (C) Representative flow cytometric profiles and (D) the percentage of $\mathrm{CD} 88^{+} \mathrm{IFN}-\gamma^{+} \mathrm{T}$ cells in splenocytes and peripheral lymph node cells gated on $\mathrm{CD} 3^{+} \mathrm{CD} 8^{+} \mathrm{T}$ cells are shown. Data are representative of at least three independent experiments and are shown as means $\pm \mathrm{SD} ;{ }^{*} \mathrm{p}<0.05,{ }^{* *} \mathrm{p}<0.01$.

The CD4 ${ }^{+} \mathrm{IFN}-\gamma^{+}$and $\mathrm{CD} 8^{+} \mathrm{IFN}-\gamma^{+} \mathrm{T}$ cells were both most significantly increased $(\mathrm{p}<0.01)$ in the mice immunized with the Colon 26/Ag85A-CD226 tumor cell vaccine in both splenocytes and peripheral lymph node cells, followed by the Colon 26/Ag85A vaccine, the Colon 26/CD226 vaccine, the Colon 26/pcDNA3.1 and the Colon 26 vaccine (Fig. 6), indicating that the Colon 26/Ag85A-CD226 tumor cell vaccine enhanced a Th1 cell-dominated antitumor immune response.

\section{Discussion}

In immunotherapy, antitumor vaccines represent one of the most promising therapeutic strategies. To enhance the immune response, cancer vaccines are usually administered with adjuvants, such as co-stimulatory molecules and are often combined with cytokines, such as granulocyte macrophage colony-stimulating factor (GM-CSF) or interleukin (IL)-2 (23). 
Recently, genetically modified cells have been shown to be one of the most effective cancer vaccine strategies, which has been applied to various types of cancer in preclinical models, including some that are being tested in clinical trials (24-26). The Colon 26 cell vaccine expressing Ag85A and CD226 in the present study was designed to evaluate the inclusion of Ag85A as an immune enhancer, yet also takes into account the role of $\mathrm{CD} 226$. As a co-stimulatory and adhesion molecule in the activation and proliferation of T cells, CD226 promotes the initial differentiation of T to Th1 cells and boosts CTL cytotoxicity $(17,27)$. In cancer immunotherapy, the general concept is that a Th1 cell skewed response directed against a tumor is favorable. The Th1 cell response leads to the activation of tumor-specific CTL that are capable of killing or impairing the proliferation of tumor cells (28). One study of a colon cancer vaccine has shown that Th1 cell responses are essential in cancer immunotherapy and indicates the therapeutic potential of a vaccine (29).

These different therapeutic Colon 26 colon tumor efficacies in mice indicated that tumor appearance was delayed, tumor growth was inhibited, tumor volume and weight were decreased and the survival time of the tumor-bearing mice was extended, particularly in the Colon 26/Ag85A-CD226 tumor cell vaccine group. We speculated that the therapeutic effects that we observed in mice depended mainly on immune responses, in particular an enhanced Th1 cell-dominated cellular immune response. This model is supported by the enhanced NK cell and CTL cytotoxicity, increased IFN- $\gamma$ levels in splenocytes and more abundant $\mathrm{CD} 4^{+} \mathrm{IFN}-\gamma^{+}$and $\mathrm{CD} 8^{+} \mathrm{IFN}-\gamma^{+} \mathrm{T}$ cells in splenocytes and peripheral lymph node cells in mice treated with the Colon 26/Ag85A-CD226 tumor cell vaccine. The enhanced non-specific killing activities of NK cells and tumor-specific killing activities of CTL led to increased necrosis in tumor tissues. Furthermore, the tumor infiltrating $\mathrm{CD}^{+}$or $\mathrm{CD}^{+} \mathrm{T}$ cells in tumor tissues led to increased apoptosis of tumor cells in the Colon 26/Ag85A-CD226 tumor cell vaccine group. The present study also indicated that the immune responses induced by the Colon 26/Ag85A-CD226 vaccine were significantly stronger than Colon 26/Ag85A, and then we speculated that CD226 played a genetic adjuvant role to promote the immune responses induced by $\mathrm{Ag} 85 \mathrm{~A}$ in anti-Colon 26 colon carcinoma.

In summary, the present study demonstrated that the tumor vaccine with co-expression of CD226 and Ag85A induced more intensive antitumor immunity than the tumor vaccine expressing Ag85A or CD226 only. Our investigation suggests that $\mathrm{Ag} 85 \mathrm{~A}$ and $\mathrm{CD} 226$ play a synergistic role in anti-Colon 26 colon carcinoma immune responses and CD226 could be used as a genetic adjuvant to enhance the effects of the Ag85A vaccine against tumors. Our findings establish a new strategy for the development of a novel vaccine against colon carcinoma.

\section{Acknowledgements}

We kindly thank Professor Shibuya in University of Tsukuba in Japan for providing CD226-PCR2.1-ToPo. This study was financially supported by the National Natural Science Foundation of China (no. 31270972), and the Natural Science Foundation of Liaoning Province of China (no. 2011415052-1).

\section{References}

1. Esteban-Jurado C, Garre P, Vila M, Lozano JJ, Pristoupilova A, Beltrán S, Abulí A, Muñoz J, Balaguer F, Ocaña T, et al: New genes emerging for colorectal cancer predisposition. World $\mathrm{J}$ Gastroenterol 20: 1961-1971, 2014.

2. Li HZ, Mao WM, Wang XH, Yu CD and Du LB: Incidence and mortality of cancer in Zhejiang province in 2009. Zhonghua Yu Fang Yi Xue Za Zhi 47: 592-596, 2013 (In Chinese).

3. Yi N, Xiao MB, Ni WK, Jiang F, Lu CH and Ni RZ: High expression of peroxiredoxin 4 affects the survival time of colorectal cancer patients, but is not an independent unfavorable prognostic factor. Mol Clin Oncol 2: 767-772, 2014.

4. Yang Z, Bai Y, Huo L, Chen H, Huang J, Li J, Fan X, Yang Z, Wang $\mathrm{L}$ and Wang J: Expression of A disintegrin and metalloprotease 8 is associated with cell growth and poor survival in colorectal cancer. BMC Cancer 14: 568, 2014.

5. Kim J, Huynh R, Abraham I, Kim E and Kumar RR: Number of lymph nodes examined and its impact on colorectal cancer staging. Am Surg 72: 902-905, 2006.

6. Jemal A, Center MM, DeSantis C and Ward EM: Global patterns of cancer incidence and mortality rates and trends. Cancer Epidemiol Biomarkers Prev 19: 1893-1907, 2010.

7. Belisle JT, Vissa VD, Sievert T, Takayama K, Brennan PJ and Besra GS: Role of the major antigen of Mycobacterium tuberculosis in cell wall biogenesis. Science 276: 1420-1422, 1997.

8. Huygen K, Content J, Denis O, Montgomery DL, Yawman AM, Deck RR, DeWitt CM, Orme IM, Baldwin S, D'Souza C, et al: Immunogenicity and protective efficacy of a tuberculosis DNA vaccine. Nat Med 2: 893-898, 1996.

9. Borremans M, de Wit L, Volckaert G, Ooms J, de Bruyn J, Huygen K, van Vooren JP, Stelandre M, Verhofstadt R and Content J: Cloning, sequence determination, and expression of a 32-kilodalton-protein gene of Mycobacterium tuberculosis. Infect Immun 57: 3123-3130, 1989.

10. Montgomery DL, Huygen K, Yawman AM, Deck RR, Dewitt CM, Content J, Liu MA and Ulmer JB: Induction of humoral and cellular immune responses by vaccination with $M$. tuberculosis antigen 85 DNA. Cell Mol Biol (Noisy-le-grand) 43: 285-292, 1997.

11. Dou J, Tang Q, Yu F, Yang H, Zhao F, Xu W, Wang J, Hu W, Hu K and Liou C: Investigation of immunogenic effect of the BCG priming and Ag85A-GM-CSF boosting in Balb/c mice model. Immunobiology 215: 133-142, 2010.

12. Dou J, Wang Y, Yu F, Yang H, Wang J, He X, Xu W, Chen J and Hu K: Protection against Mycobacterium tuberculosis challenge in mice by DNA vaccine Ag85A-ESAT-6-IL-21 priming and BCG boosting. Int J Immunogenet 39: 183-190, 2012.

13. Wang D, Xu J, Feng Y, Liu Y, Mchenga SS, Shan F, Sasaki J and Lu C: Liposomal oral DNA vaccine (mycobacterium DNA) elicits immune response. Vaccine 28: 3134-3142, 2010.

14. Liu CS, Wu Y, Dou J, Wen P, Zhao FS, Tang Q, Li JL and Wang YQ: Study of anti-melanoma effect in mice injected with melanoma cells transfected with the recombinant expressing Ag85A and GM-CSF. J Southeast Univ 29: 57-61, 2010.

15. Zhang P, Wang J, Wang D, Wang H, Shan F, Chen L, Hou Y, Wang E and Lu CL: Dendritic cell vaccine modified by Ag85A gene enhances anti-tumor immunity against bladder cancer. Int Immunopharmacol 14: 252-260, 2012.

16. Shibuya A, Campbell D, Hannum C, Yssel H, Franz-Bacon K, McClanahan T, Kitamura T, Nicholl J, Sutherland GR, Lanier LL, et al: DNAM-1, a novel adhesion molecule involved in the cytolytic function of T lymphocytes. Immunity 4: 573-581, 1996.

17. Shirakawa J, Shibuya K and Shibuya A: Requirement of the serine at residue 329 for lipid raft recruitment of DNAM-1 (CD226). Int Immunol 17: 217-223, 2005.

18. Seth S, Georgoudaki AM, Chambers BJ, Qiu Q, Kremmer E, Maier MK, Czeloth N, Ravens I, Foerster R and Bernhardt G: Heterogeneous expression of the adhesion receptor CD226 on murine NK and T cells and its function in NK-mediated killing of immature dendritic cells. J Leukoc Biol 86: 91-101, 2009.

19. Li Y, Yang F, Zhu J, Sang L, Han X, Wang D, Shan F, Li S, Sun $X$ and Lu C: CD226 as a genetic adjuvant to enhance immune efficacy induced by Ag85A DNA vaccination. Int Immunopharmacol 25: 10-18, 2015. 
20. Tuominen VJ, Ruotoistenmäki S, Viitanen A, Jumppanen M and Isola J: ImmunoRatio: A publicly available web application for quantitative image analysis of estrogen receptor (ER), progesterone receptor (PR), and Ki-67. Breast Cancer Res 12: R56, 2010.

21. Marcusson-Ståhl M and Cederbrant K: A flow-cytometric NK-cytotoxicity assay adapted for use in rat repeated dose toxicity studies. Toxicology 193: 269-279, 2003.

22. Zhao F, Dou J, Wang J, Chu L, Tang Q, Wang Y, Li Y, Cao M, $\mathrm{Hu} \mathrm{W}$ and $\mathrm{Hu} \mathrm{K}$ : Investigation on the anti-tumor efficacy by expression of GPI-anchored mIL-21 on the surface of B16F10 cells in C57BL/6 mice. Immunobiology 215: 89-100, 2010.

23. Clive KS, Tyler JA, Clifton GT, Holmes JP, Mittendorf EA, Ponniah S and Peoples GE: Use of GM-CSF as an adjuvant with cancer vaccines: Beneficial or detrimental? Expert Rev Vaccines 9: 519-525, 2010.

24. Miguel A, Herrero MJ, Sendra L, Botella R, Algás R, Sánchez M and Aliño SF: Comparative antitumor effect among GM-CSF, IL-12 and GM-CSF+IL-12 genetically modified tumor cell vaccines. Cancer Gene Ther 20: 576-581, 2013.

25. Olivares J, Kumar P, Yu Y, Maples PB, Senzer N, Bedell C, Barve M, Tong A, Pappen BO, Kuhn J, et al: Phase I trial of TGF-beta 2 antisense GM-CSF gene-modified autologous tumor cell (TAG) vaccine. Clin Cancer Res 17: 183-192, 2011.
26. Agarwalla P, Barnard Z, Fecci P, Dranoff G and Curry WT Jr: Sequential immunotherapy by vaccination with GM-CSFexpressing glioma cells and CTLA-4 blockade effectively treats established murine intracranial tumors. J Immunother 35: 385-389, 2012.

27. Seth S, Qiu Q, Danisch S, Maier MK, Braun A, Ravens I, Czeloth N, Hyde R, Dittrich-Breiholz O, Förster R, et al: Intranodal interaction with dendritic cells dynamically regulates surface expression of the co-stimulatory receptor CD226 protein on murine T cells. J Biol Chem 286: 39153-39163, 2011.

28. Burgdorf SK, Claesson MH, Nielsen HJ and Rosenberg J: Changes in cytokine and biomarker blood levels in patients with colorectal cancer during dendritic cell-based vaccination. Acta Oncol 48: 1157-1164, 2009.

29. Nishimura T, Nakui M, Sato M, Iwakabe K, Kitamura H, Sekimoto M, Ohta A, Koda T and Nishimura S: The critical role of Th1-dominant immunity in tumor immunology. Cancer Chemother Pharmacol 46 (Suppl): S52-S61, 2000. 